\title{
HOW DOES THE NEW KEYNESIAN MONETARY MODEL FIT IN THE U.S. AND THE EUROZONE? AN INDIRECT INFERENCE APPROACH*
}

\author{
Ramón María-Dolores* and Jesús Vázquez ${ }^{* *}, \dagger$ \\ Universidad de Murcia* and Universidad del País Vasco ${ }^{* *}$
}

May 2005

Key words: Indirect inference, NKM model, Taylor rule, optimal policy JEL classification numbers: C32, E30, E52

\footnotetext{
*We are grateful to Arantza Gorostiaga, Antonio Moreno, Luis Puch, Marta Regúlez and seminar participants at FEDEA and Universidad del País Vasco for comments. Financial support from Ministerio de Ciencia y Tecnología and Universidad del País Vasco (Spain) through projects SEJ2004-04811/ECON and 9/UPV00035.321-13511/2001, respectively, is gratefully acknowledged.

†Correspondence to: Jesús Vázquez, Departamento de Fundamentos del Análisis Económico II, Universidad del País Vasco, Av. Lehendakari Aguirre 83, 48015 Bilbao, Spain. Phone: (34) 94-601-3779, Fax: (34) 94-601-3774, e-mail: jepvapej@bs.ehu.es
} 


\begin{abstract}
This paper estimates a standard version of the New Keynesian monetary (NKM) model under alternative specifications of the monetary policy rule using U.S. and Eurozone data. The estimation procedure implemented is a classical method based on the indirect inference principle. An unrestricted VAR is considered as the auxiliary model. On the one hand, the estimation method proposed overcomes some of the shortcomings of using a structural VAR as the auxiliary model in order to identify the impulse response that defines the minimum distance estimator implemented in the literature. On the other hand, by following a classical approach we can further assess the estimation results found in recent papers that follow a maximum-likelihood Bayesian approach. The estimation results show that some structural parameter estimates are quite sensitive to the specification of monetary policy. Moreover, the estimation results in the U.S. show that the fit of the NKM under an optimal monetary plan is much worse than the fit of the NKM model assuming a forward-looking Taylor rule. In contrast to the U.S. case, in the Eurozone the best fit is obtained assuming a backward-looking Taylor rule, but the improvement is rather small with respect to assuming either a forward-looking Taylor rule or an optimal plan.
\end{abstract}




\section{INTRODUCTION}

The New Keynesian monetary (NKM) model has become the workhorse for analyzing short-run fluctuations and the effects of monetary policy. Many papers have estimated versions of the NKM model for many purposes. ${ }^{1}$ Two general approaches have been followed in the literature for estimating dynamic stochastic general equilibrium models such as the NKM model. Rotemberg and Woodford (1997) estimate the NKM model by minimizing a distance function between the impulse response functions obtained from actual data and those derived from synthetic data (i.e., data generated by the model). A similar approach is followed by Amato and Laubach (2003) and Boivin and Giannoni (2003). Alternatively, Lubik and Schorfheide (2004), Smets and Wouters (2003), Canova (2004) and Rabanal and Rubio-Ramírez (2005), among others, follow a full information maximum-likelihood Bayesian approach.

The aim of this paper is to estimate a standard version of the NKM model under four alternative monetary policy rules. The first three monetary rules are Taylor rules where the lagged interest rate is included and the difference between them is whether the current interest rate reacts to current, expected or lagged values of inflation and output gap. We call them standard, forward-looking and backward-looking Taylor rules, respectively. We also estimate the NKM model under the assumption that the Central Bank follows an "optimal" plan where the parameters characterizing its loss function are considered as free parameters in the estimation.

We wonder first whether structural parameter estimates are robust to alternative specifications of monetary policy and, second, which monetary rule provides the best fit to the data. An answer in the affirmative to the first question implies that the evaluation of alternative monetary policies is simpler because robust structural estimates imply lower uncertainty about structural parameter values. The second question posited is important because we want to analyze whether monetary policy is forward-looking and how optimal monetary policy is. In a similar vein María-Dolores and Vázquez (2004) show that in order to reproduce the comovement between output and inflation in the U.S., the type of Taylor rule assumed in the NKM model has

\footnotetext{
${ }^{1}$ Some examples of this rapidly growing literature follow. Rotemberg and Woodford (1997) and Galí and Gertler (1999) analyze inflation dynamics and evaluate monetary policy. Lubik and Schorfheide (2004) estimate the model for testing for indeterminacy. Boivin and Giannoni (2003) and Canova (2004) estimate the model for testing the stability of monetary policy parameters and the transmission mechanism of policy shocks. These papers use U.S. data. See also Smets and Wouters (2003) for an expanded version of the standard NKM model of the Eurozone.
} 
to be consistent with the relative importance of forward-looking components characterizing the private sector behavior.

We follow a classical approach based on the indirect inference principle suggested by Gouriéroux, Monfort and Renault (1993), Smith (1993) and Gallant and Tauchen (1996) to estimate the NKM model under alternative specifications of monetary policy. ${ }^{2}$ As in the first approach mentioned above, we use an (unrestricted) VAR as the auxiliary model, ${ }^{3}$ but the distance function is built upon the coefficients estimated from a three-variable VAR instead of upon the impulse response functions. We pay attention to the VAR coefficients for three main reasons. First, the alternative versions of the NKM model can be represented as a restricted VAR. Therefore, the unrestricted VAR used as the auxiliary model nests any version of the model considered. Second, obtaining sensible impulse response functions usually requires the inclusion of additional variables. For instance, to solve the so called price puzzle a commodity price index or an asset price is included in the impulse response analysis even though the NKM model is silent about how either the commodity price index or any asset price is determined. Finally (and more technically), applications of the minimum distance estimator based on impulse response functions use a diagonal weighting matrix that includes the inverse of each impulse response's variance on the main diagonal. This weighting matrix delivers consistent estimates of the structural parameters, but it is not asymptotically efficient since it does not take into account the whole covariance matrix structure associated with the set of moments. ${ }^{4} \mathrm{We}$ consider the VAR coefficients as the set of moments in order to implement the minimum distance estimator. Then, an estimator of the efficient weighting matrix is found to be straightforward. ${ }^{5}$ Moreover, all parameters are estimated in our application and the only restrictions imposed in the esti-

\footnotetext{
${ }^{2}$ See also Gouriéroux and Monfort (1996) for a monograph on simulation-based econometric methods.

${ }^{3}$ Gourieroux, Monfort and Renault (1993), Smith(1993), and Gutiérrez and Vázquez (2004) show applications of the indirect inference principle using a parametric auxiliary model. Gallant and Tauchen (1996), Gallant, Hsieh and Tauchen (1997) consider seminonparametric models as an auxiliary model. They call this latter approach the "efficient method of moments" since the idea is to reach asymptotic efficiency by choosing a flexible auxiliary model capable of providing a good approximation for any distribution by increasing the number of auxiliary parameters.

${ }^{4}$ Boivin and Giannoni (2003) indicate this drawback, but provide no alternative. Canova (2004) points out two additional drawbacks in some applications of the minimum distance estimator. First, fixing parameters that are hard to estimate. Second, arbitrarily constraining the search for the maximum.

${ }^{5}$ See Duffie and Singleton (1993, p.939) for a discussion on the choice of a weighting matrix in order to obtain asymptotic efficient estimates.
} 
mation are those imposed by economic theory. Namely, all parameters are non-negative and a subset of them belongs to the interval $[0,1)$.

By following a classical approach, we obviously depart from papers that use a Bayesian approach. We believe that a Bayesian approach is appropriate for answering many questions when the main focus is, for instance, the analysis of the effects of monetary policy and the researcher has strong priors about certain structural parameter values (say, for instance, that the discount factor parameter is around 0.99 with high probability when using quarterly data). But we also think that a classical approach is useful when a researcher's knowledge of model specification and parameter values is less precise and one wants to analyze the sensitivity of structural parameters to alternative model specifications, or alternatively when one wants to analyze whether a given set of priors are confirmed by the data without imposing them in the estimation procedure. Under this view the classical and Bayesian methods should be viewed as complementary approaches.

The main estimation results can be summarized as follows. They show that several parameter estimates are quite sensitive to the specification of the monetary policy rule. For instance, the estimates of the relative risk aversion parameter and the slope of the Phillips curve are rather sensitive to the specification of the Taylor rule in the U.S., but not in the Eurozone. Moreover, the estimation results in the U.S. show that the fit of the NKM under an optimal monetary plan is worse than the fit of the NKM model assuming a forward-looking Taylor rule. In contrast to the U.S. case, the best fit in the Eurozone is obtained assuming a backward-looking Taylor rule, but the improvement is rather small with respect to assuming either a forward-looking Taylor rule or an optimal plan. Furthermore, our estimation results suggest that the standard deviations of certain parameter estimates are much larger than those obtained using Bayesian methods where for other parameters (for instance, the discount factor and the inertial parameter of the Taylor rule) they are similar under the two approaches. Diagnostic tests also suggest that the NKM model has trouble in accounting for inflation persistence in actual data as largely documented in the literature as well as for output gap and interest rate persistence.

The rest of the paper is organized as follows. Section 2 introduces the log-linearized approximation of a standard version of the NKM model and presents four alternative specifications for the monetary rule widely used in the literature. Section 3 describes the structural estimation method used in this paper. Section 4 presents and discusses the estimation results, and provides diagnostic tests to identify features of the data that the NKM model does not account for. Section 5 concludes. 


\section{THE NEW KEYNESIAN MONETARY MODEL}

The model analyzed in this paper is a standard version of the NKM model, which is given by the following set of equations:

$$
\begin{gathered}
y_{t}=E_{t} y_{t+1}-\tau\left(i_{t}-E_{t} \pi_{t+1}\right)+g_{t}, \\
\pi_{t}=\beta E_{t} \pi_{t+1}+\kappa y_{t}+z_{t}, \\
i_{t}=\rho i_{t-1}+(1-\rho)\left(\psi_{1} \pi_{t}+\psi_{2} y_{t}\right)+\epsilon_{i t} .
\end{gathered}
$$

where $y, \pi$ and $i$ denote the log-deviations from the steady states of output, inflation and nominal interest rate, respectively. $E_{t}$ denotes the conditional expectation based on the agents' information set at time $t . g$ and $z$ denote aggregate demand and aggregate supply shocks, respectively. These two shocks are further assumed to follow first-order autoregressive process

$$
\begin{aligned}
& g_{t}=\rho_{g} g_{t-1}+\epsilon_{g t}, \\
& z_{t}=\rho_{z} z_{t-1}+\epsilon_{z t},
\end{aligned}
$$

where $\epsilon_{g t}$ and $\epsilon_{z t}$ denote i.i.d. random shocks.

Equation (1) is the log-linearized consumption first-order condition obtained from the representative agent optimization plan. The parameter $\tau>0$ represents the intertemporal elasticity of substitution obtained when assuming a standard constant relative risk aversion utility function.

Equation (2) is the new Phillips curve that is obtained in a sticky price à la Calvo (1983) model where monopolistically competitive firms produce (a continuum of) differentiated goods and each firm faces a downward sloping demand curve for its produced good. The parameter $\beta \in(0,1)$ is the agent discount factor and $\kappa$ measures the slope of the New Phillips curve. ${ }^{6}$

Equation (3) is a standard Taylor-type monetary rule where the nominal interest rate exhibits smoothing behavior, captured by parameter $\rho$, for which there are several motivating arguments in the literature. These arguments range from the traditional concern of central banks for the stability of financial markets (see Goodfriend, 1991 and Sacks, 1997) to the more psychological one posed by Lowe and Ellis (1997), who argue that there might

\footnotetext{
${ }^{6}$ Early versions of the NKM models include those of Yun (1996), Goodfriend and King (1997), Rotemberg and Woodford (1995, 1997) and McCallum and Nelson (1999). See also Galí (2002) for a detailed analytical derivation of a standard version of the NKM model.
} 
be a political incentive for smoothing whenever policymakers are likely to be embarrassed by reversals in the direction of interest-rate changes if they believe that the public may interpret them as repudiations of previous actions. By contrast, a series of interest-rate changes in the same direction looks like a well-designed programme, and that may give rise to the sluggish behavior of the intervention interest rate. Moreover, Taylor rule (3) assumes that the nominal interest rate responds to current deviations of output and inflation from their respective steady state values. Later on, we shall consider a backward-looking Taylor rule, a forward-looking Taylor rule and an optimal monetary plan.

The system of equations (1)-(5) can be written in matrix form as follows

$$
\Gamma_{0} \xi_{t}=\Gamma_{1} \xi_{t-1}+\Psi \epsilon_{t}+\Pi \eta_{t},
$$

where

$$
\begin{aligned}
& \xi_{t}=\left(y_{t}, \pi_{t}, i_{t}, E_{t} y_{t+1}, E_{t} \pi_{t+1}, g_{t}, z_{t}\right)^{\prime} \\
& \epsilon_{t}=\left(\epsilon_{i t}, \epsilon_{g t}, \epsilon_{z t}\right)^{\prime}, \\
& \eta_{t}=\left(y_{t}-E_{t-1}\left[y_{t}\right], \pi_{t}-E_{t-1}\left[\pi_{t}\right]\right)^{\prime} \\
& \Gamma_{0}=\left(\begin{array}{ccccccc}
-1 & 0 & -\tau & 1 & \tau & 1 & 0 \\
k & -1 & 0 & 0 & \beta & 0 & 1 \\
-(1-\rho) \psi_{2} & -(1-\rho) \psi_{1} & 1 & 0 & 0 & 0 & 0 \\
0 & 0 & 0 & 0 & 0 & 1 & 0 \\
0 & 0 & 0 & 0 & 0 & 0 & 1 \\
1 & 0 & 0 & 0 & 0 & 0 & 0 \\
0 & 1 & 0 & 0 & 0 & 0 & 0
\end{array}\right) \\
& \Gamma_{1}=\left(\begin{array}{ccccccc}
0 & 0 & 0 & 0 & 0 & 0 & 0 \\
0 & 0 & 0 & 0 & 0 & 0 & 0 \\
0 & 0 & \rho & 0 & 0 & 0 & 0 \\
0 & 0 & 0 & 0 & 0 & \rho_{g} & 0 \\
0 & 0 & 0 & 0 & 0 & 0 & \rho_{z} \\
0 & 0 & 0 & 1 & 0 & 0 & 0 \\
0 & 0 & 0 & 0 & 1 & 0 & 0
\end{array}\right)
\end{aligned}
$$




$$
\begin{aligned}
\Pi & =\left(\begin{array}{ll}
0 & 0 \\
0 & 0 \\
0 & 0 \\
0 & 0 \\
0 & 0 \\
1 & 0 \\
0 & 1
\end{array}\right), \\
\Psi & =\left(\begin{array}{lll}
0 & 0 & 0 \\
0 & 0 & 0 \\
1 & 0 & 0 \\
0 & 1 & 0 \\
0 & 0 & 1 \\
0 & 0 & 0 \\
0 & 0 & 0
\end{array}\right) .
\end{aligned}
$$

Equation (6) represents a linear rational expectations (LRE) system. It is well known that LRE systems deliver multiple stable equilibrium solutions for certain parameter values. Lubik and Schorfheide (2003) characterize the complete set of LRE models with indeterminacies and provide a numerical method for computing them that builds on Sims' (2002) approach. ${ }^{7}$ In this paper, we deal only with sunspot-free equilibria. ${ }^{8}$

We now extend the analysis to consider alternative monetary policy rules studied in the literature. First, we consider a Taylor rule where the nominal interest rate responds to expected deviations of inflation and output from their respective steady state levels, which describes how the central bank may react to anticipated movements in output and inflation. Formally, the forward-looking Taylor rule is given by

$$
i_{t}=\rho i_{t-1}+(1-\rho)\left(\psi_{1} E_{t} \pi_{t+1}+\psi_{2} E_{t} y_{t+1}\right)+\epsilon_{i t} .
$$

Second, a backward-looking Taylor rule is considered where the nominal interest rate responds to lagged deviations of output and inflation from their

\footnotetext{
${ }^{7}$ The GAUSS code for computing equilibria of LRE models can be found on Frank Schorfheide's website.

${ }^{8}$ Lubik and Schorfheide (2003) deal with multiple equilibria by assuming that agents observe an exogenous sunspot shock $\zeta_{t}$, in addition to the fundamental shocks, $\epsilon_{t}$. Since an LRE system such as (6) is linear, the forecast errors, $\eta_{t}$, can be expressed as a linear function of $\epsilon_{t}$ and $\zeta_{t}: \eta_{t}=A_{1} \epsilon_{t}+A_{2} \zeta_{t}$, where $A_{1}$ is $2 \times 3$ and $A_{2}$ is $2 \times 1$ in this model. There are three possible scenarios: (i) No stable equilibrium. (ii) A unique stable equilibrium in which $A_{1}$ is completely determined by the structural parameters of the model and $A_{2}=0$. (iii) Multiple stable equilibria in which $A_{1}$ is not uniquely determined by the structural parameters of the model and $A_{2}$ can be non-zero. In the latter case, one can deal only with a stable sunspot-free equilibrium by imposing $A_{2}=0$ and then the corresponding equilibrium can be understood as a sunspot equilibrium without sunspots.
} 
respective steady state values as a way of capturing delays in information flows. Formally,

$$
i_{t}=\rho i_{t-1}+(1-\rho)\left(\psi_{1} \pi_{t-1}+\psi_{2} y_{t-1}\right)+\epsilon_{i t} .
$$

Once the benchmark NKM model has been solved, solving the NKM model with either of these two alternative Taylor rules only requires replacing equation (3) by (7) or (8), which amounts only to slight modifications of matrices $\Gamma_{0}$ and $\Gamma_{1}$.

Finally, we analyze the optimal plan for the Central Bank. Closely following Woodford (2003) and Giannoni and Woodford (2003), we assume that the Central Bank minimizes the expected value of a loss criterion of the form

$$
W=E_{0}\left[\sum_{t=0}^{\infty} \beta^{t} L_{t}\right],
$$

where the loss in each period is given by ${ }^{9}$

$$
L_{t}=\frac{1}{2}\left(\pi_{t}^{2}+\lambda_{y} y_{t}^{2}+\lambda_{i} i_{t}^{2}\right) .
$$

In order to characterize the optimal plan it is useful to write the Lagrangian associated with the optimal control problem for the Central Bank ${ }^{10}$

$$
\begin{aligned}
& E_{0}\left\{\sum _ { t = 0 } ^ { \infty } \beta ^ { t } \left\{L_{t}+\mu_{1 t}\left[y_{t}-y_{t+1}+\tau\left(i_{t}-\pi_{t+1}\right)-g_{t}\right]\right.\right. \\
& \left.\left.+\mu_{2 t}\left[\pi_{t}-\beta \pi_{t+1}-\kappa y_{t}-z_{t}\right]\right\}\right\}
\end{aligned}
$$

An optimal plan must satisfy the following F.O.C.: ${ }^{11}$

$$
\begin{gathered}
E_{t}\left(\pi_{t}-\tau \beta^{-1} \mu_{1 t-1}+\mu_{2 t}-\mu_{2 t-1}\right)=0, \\
E_{t}\left(\lambda_{y} y_{t}+\mu_{1 t}-\beta^{-1} \mu_{1 t-1}-\kappa \mu_{2 t}\right)=0, \\
\lambda_{i} i_{t}+\mu_{1 t} \tau=0
\end{gathered}
$$

\footnotetext{
${ }^{9}$ We have also investigated a loss criterion function that includes an additional term $\lambda_{\Delta}\left(i_{t}-i_{t-1}\right)^{2}$ in order to control for explicit central bank preferences on interest rate smoothing. The estimation results (available from the authors upon request) show that $\lambda_{\Delta}$ is not significant for the U.S. and the Eurozone.

${ }^{10} \mathrm{By}$ the law of iterated expectations, the conditional expectation operators inside the restrictions are removed.

${ }^{11}$ As is well known, the optimal plan obtained from these conditions will, in general, not be time consistent as discussed by Kydland and Prescott (1977).
} 
obtained by differentiating the Lagrangian with respect to $\pi_{t}, y_{t}$ and $i_{t}$, respectively. Under the optimal plan these conditions must hold at each $t$ $\geq 0$ together with initial conditions

$$
\mu_{1,-1}=\mu_{2,-1}=0 \text {. }
$$

To solve the NKM model under optimal monetary policy the solution must be found for the system formed by equations (1), (2), (4), (5), (9), (10) and (11). This solution is derived in Appendix 1.

\section{ESTIMATION PROCEDURE}

In order to estimate the structural and policy parameters of the NKM model, we follow the indirect inference principle proposed by Gourierroux, Monfort and Renault (1993), Smith (1993), and Gallant and Tauchen (1996). A VAR representation is considered as the auxiliary model. ${ }^{12}$ More precisely, we first estimate a three-variable VAR with four lags in order to summarize the joint dynamics exhibited by quarterly data of output gap, inflation, and short-term interest rate in the U.S. and the Eurozone. Second, we apply the simulated moments estimator (SME) suggested by Lee and Ingram (1991) and Duffie and Singleton (1993) to estimate the underlying structural and policy parameters of the NKM model.

The use of this estimation strategy is especially appropriate in this context for three main reasons. ${ }^{13}$ First, the NKM model is a highly stylized model of a complex world and this model is then going to be rejected with probability one when using a test with sufficient power. Therefore, maximum-likelihood estimation of the restricted VAR model implied by the NKM model may not be appropriate. In Cochrane's (2001, p. 293) words "[maximum likelihood] does the "right" efficient thing if the model is true. It does not necessarily do the "reasonable" thing for "approximate" models." Second, macroeconomic variables such as output gap, inflation and interest rates show a great deal of persistence. Since VAR's are well suited to deal with persistence an unrestricted VAR is a good candidate as the auxiliary model in this context. Finally, the VAR auxiliary model nests the alternative versions of the NKM

\footnotetext{
${ }^{12}$ Cassou (1989) is an early application of the indirect inference principle using a VAR as the auxiliary model in the estimation of a dynamic stochastic general equilibrium model.

${ }^{13}$ At this point, the reader may have the following three questions in mind. Why do we not estimate the NKM model by maximun-likelihood directly? Why do we use a VAR as the auxiliary model? What do we learn from the estimation of the NKM model based on the indirect inference principle? This paragraph answers these three questions.
} 
model considered. As shown by Gallant and Tauchen (1996), if the auxiliary model nests the structural model then the estimator is as efficient as maximum likelihood. Moreover, the estimation approach based on the indirect inference principle may help to identify which structural parameter estimates are forced to go outside of the economically reasonable support (for instance, the prior distribution support used by Bayesian estimator applications) in order to achieve a better fit of the NKM model.

The SME makes use of a set of statistics computed from the data set used and from a number of different simulated data sets generated by the model being estimated. More specifically, the statistics used to carry out the SME are the coefficients of the four-variable VAR with four lags, which is considered as the auxiliary model in this paper. The lag length considered is fairly reasonable when using quarterly data. To implement the method, we construct a $p \times 1$ vector with the coefficients of the VAR representation obtained from actual data, denoted by $H_{T}\left(\theta_{0}\right)$, where $p$ in this application is $45,{ }^{14} \mathrm{~T}$ denotes the length of the time series data, and $\theta$ is a $k \times 1$ vector whose components are the structural parameters. The true parameter values are denoted by $\theta_{0}$. In the NKM model with a Taylor rule, the structural and policy parameters are $\theta=\left(\tau, \beta, \rho, \kappa, \psi_{1}, \psi_{2}, \rho_{g}, \rho_{z}, \sigma_{g}, \sigma_{z}, \sigma_{\varepsilon}, \pi^{*}\right)$ and then $k=12$. In the NKM model under an optimal policy plan, the structural parameters are $\theta=\left(\tau, \beta, \kappa, \lambda_{y}, \lambda_{i}, \rho_{g}, \rho_{z}, \sigma_{g}, \sigma_{z}, \pi^{*}\right)$ and then $k=10$ in this case.

Given that the real data are by assumption a realization of a stochastic process, the randomness in the estimator can be decreased by simulating the model $m$ times. For each simulation a $p \times 1$ vector of VAR coefficients, denoted by $H_{N, i}(\theta)$, is obtained from the simulated time series of output gap, inflation and interest rate generated from the NKM model, where $N=n T$ is the length of the simulated data. Averaging the $m$ realizations of the simulated coefficients, i.e., $H_{N}(\theta)=\frac{1}{m} \sum_{i=1}^{m} H_{N i}(\theta)$, we obtain a measure of the expected value of these coefficients, $E\left(H_{N i}(\theta)\right)$. Since the model is estimated many times (we estimate the model for several specifications, four alternative policy rules and two data sets), after checking the robustness of the results we make $n=m=10$ in this application. To generate simulated values of output gap, inflation and interest rate we need the starting values of these variables. For the SME to be consistent, the initial values must have been drawn from a stationary distribution. In practice, to avoid the influence of the starting values we follow Lee and Ingram's suggestion of generating a realization from the stochastic processes of the four variables of length $2 \mathrm{~N}$,

\footnotetext{
${ }^{14}$ We have 39 coefficients from a four-lag, three-variable system and 6 extra coefficients from the non-redundant elements of the variance-covariance matrix of the VAR residuals.
} 
discard the first $N$-simulated observations, and use only the remaining $N$ observations to carry out the estimation. After $N$ observations have been simulated, the influence of the initial conditions must have disappeared.

The SME of $\theta_{0}$ is obtained from the minimization of a distance function of VAR coefficients from real and simulated data. Formally,

$$
\min _{\theta} J_{T}=\left[H_{T}\left(\theta_{0}\right)-H_{N}(\theta)\right]^{\prime} W\left[H_{T}\left(\theta_{0}\right)-H_{N}(\theta)\right],
$$

where the weighting matrix $W^{-1}$ is the covariance matrix of $H_{T}\left(\theta_{0}\right)$.

Denoting the solution of the minimization problem by $\hat{\theta}$, Lee and Ingram (1991) and Duffie and Singleton (1993) prove the following results:

$$
\begin{gathered}
\sqrt{T}\left(\hat{\theta}-\theta_{0}\right) \rightarrow N\left[0,\left(1+\frac{1}{n}\right)\left(B^{\prime} W B\right)^{-1}\right], \\
\left(1+\frac{1}{n}\right) T J_{T} \rightarrow \chi^{2}(p-k),
\end{gathered}
$$

where $B$ is a full rank matrix given by $B=E\left(\frac{\partial H_{N i}(\theta)}{\partial \theta}\right) \cdot{ }^{15}$

The indirect inference approach followed in this paper resembles the method suggested by Ireland (2004) for taking dynamic stochastic general equilibrium models to data. The main difference between the two approaches is that Ireland (2004) estimates structural parameters through the estimation of a restricted VAR(1), referred to by Ireland as the hybrid model, by maximum-likelihood. Under our indirect inference approach, however, an unrestricted VAR(4) is estimated by ordinary least-squares (which is equivalent to implementing maximum-likelihood) in order to define an appropriate distance function in terms of VAR coefficients that is minimized to obtain the structural parameter estimates. The advantage of the indirect inference approach is that the auxiliary model (our choice is a VAR(4)) allows for a more flexible structure to capture persistence than the hybrid model (a VAR(1)) considered by Ireland (2004).

\footnotetext{
${ }^{15}$ The objective function $J_{T}$ is minimized using the optimization package OPTMUM programmed in GAUSS language. The Broyden-Fletcher-Glodfard-Shanno algorithm is applied. To compute the covariance matrix we need to obtain $B$. Computation of $B$ requires two steps: first, obtaining the numerical first derivatives of the coefficients of the VAR representation with respect to the estimates of the structural parameters $\theta$ for each of the $m$ simulations; second, averaging the $m$-numerical first derivatives to get $B$. The GAUSS programs for estimating the alternative versions of the NKM model studied in this paper are available from the authors upon request.
} 


\section{EMPIRICAL EVIDENCE}

\subsection{The data}

We consider quarterly U.S. data for the output gap, inflation rate obtained for the implicit GDP deflator and the Fed funds rate during the Greenspan era. ${ }^{16,17}$ Figure 1 shows the time series plots in the U.S.

For the Eurozone, we consider quarterly data since 1994 for the output gap (obtained by implementing the Hodrick-Prescott filter to the GDP time series for the period 1970:1-2004:3), the inflation rate obtained for the implicit GDP deflator and the 3-month Euribor rate. ${ }^{18}$ Figure 2 displays the time series plots for the Eurozone.

\subsection{Estimation results in the U.S.}

Table 1 and second column in Table 3 show the estimation results for the U.S. The value of the goodness-of-fit statistic, which is distributed as a $\chi^{2}(33),{ }^{19}$ confirms the hypothesis stated above that the NKM model under any specification of the policy rule considered is too stylized to be supported by actual

\footnotetext{
${ }^{16}$ We focus on the Greenspan period for several reasons. First, it allows a more straightforward comparison of the monetary policies implemented in the U.S. and the Eurozone. Second, the Taylor rule seems to fit better in this period than in the pre-Greenspan era. Third, considering the pre-Greenspan era opens the door to many issues studied in the literature, including the presence of macroeconomic switching regimes and the existence of switches in monetary policy (Sims and Zha, 2004, Cogley and Sargent, 2001, and Canova, 2004) and the presence of multiple equilibria and indeterminacy (Lubik and Schorfheide, 2004). These issues are beyond the scope of this paper.

${ }^{17}$ U.S. output gap is measured as the percentage deviation of GDP from the real potential GDP time series constructed by the U.S. Congressional Budget Office. Appendix 2 describes the sources and sample periods studied for the U.S. and the Eurozone.

${ }^{18}$ When analyzing monetary policy in the Eurozone two issues emerge. First, we cannot go back too far in time because it is then hard to justify a common policy rule in the Eurozone. Second, we have to rely on a market interest rate, such as the Euribor rate, since the length of the interest rate time series sets by the European Central Bank is too short.

${ }^{19}$ When estimating the NKM model under the optimal monetary plan the goodness-offit statistic is distributed as a $\chi^{2}(31)$ since the number of parameters being estimated is 10 instead of 12 .
} 

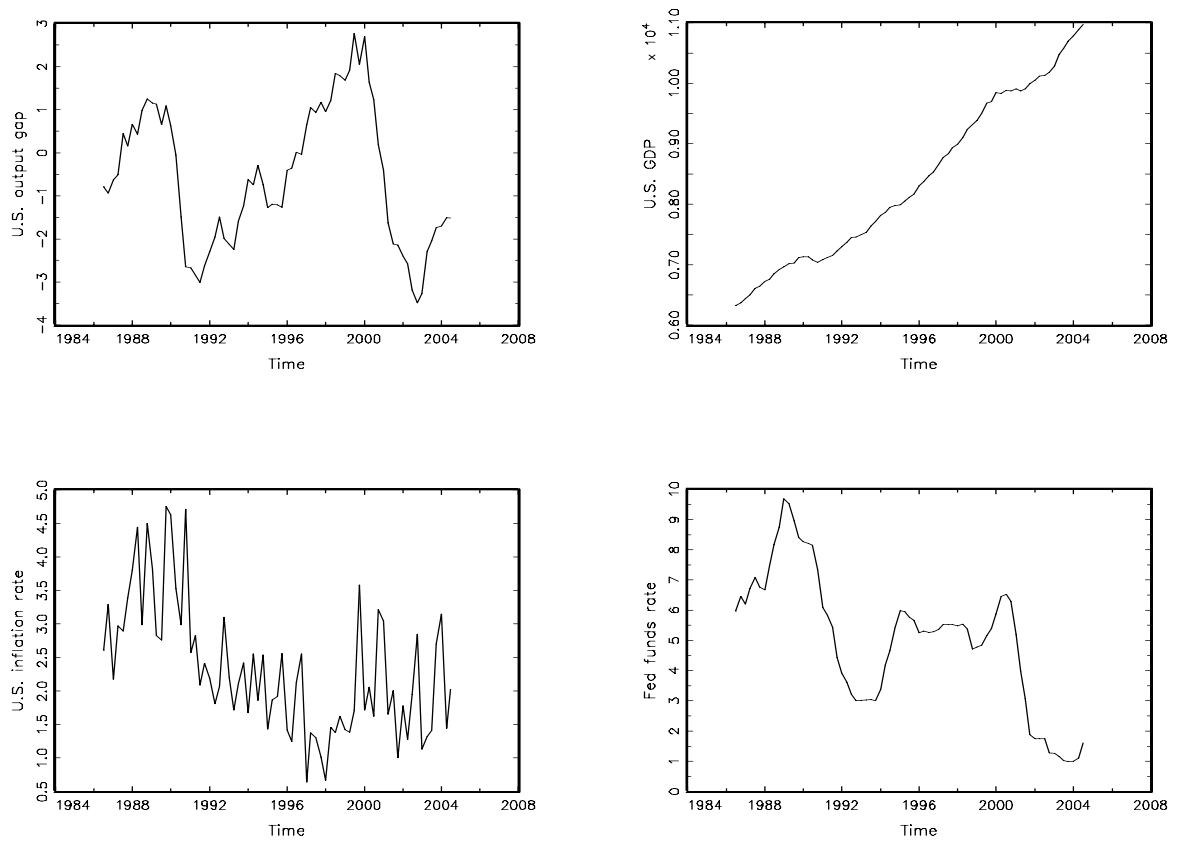

Figure 1: U.S. time series 

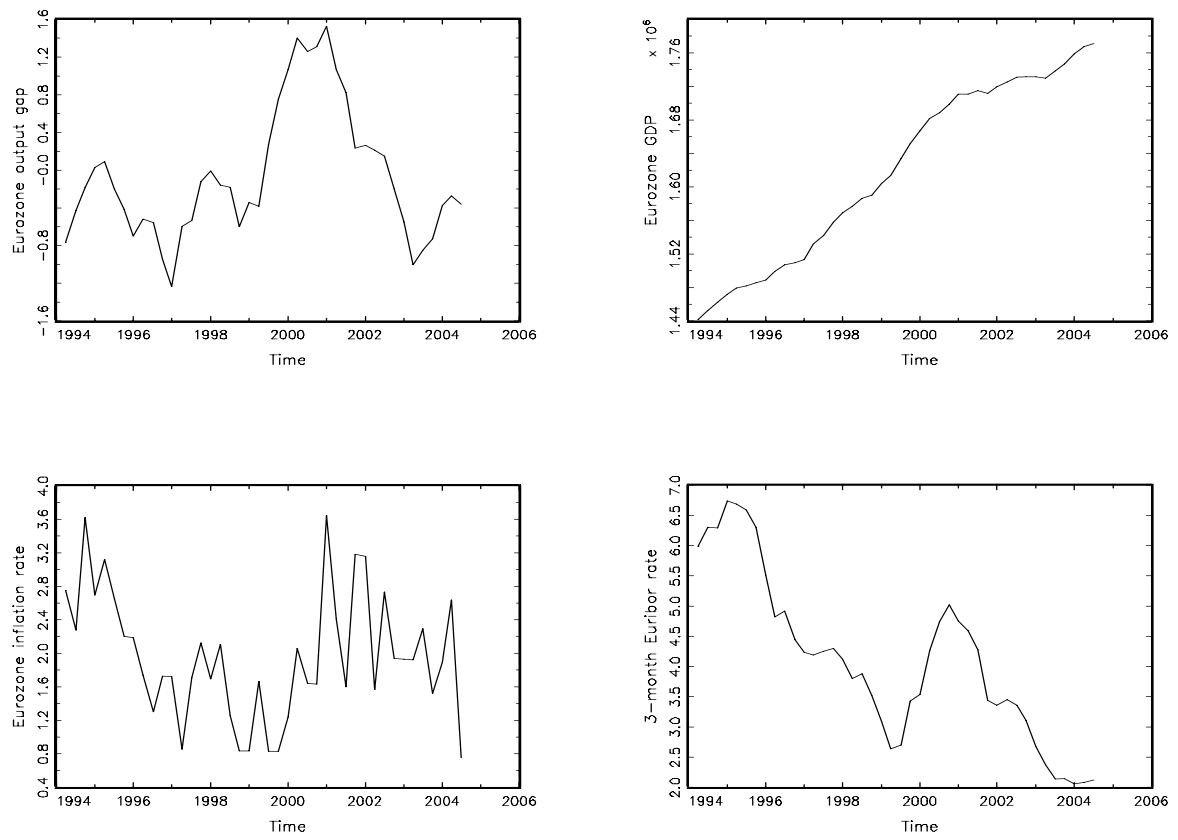

Figure 2: Eurozone time series 
data. Nevertheless, the estimation results show that the NKM model assuming a forward-looking Taylor rule improves the fit by $30 \%$ with respect to the NKM under a backward-looking Taylor rule and by roughly $40 \%$ with respect to the NKM model assuming either a standard optimal rule or an optimal monetary plan.

Among papers using Bayesian methods, slightly different estimation results are obtained for certain parameters due to differences in model specification, sample periods considered and so on. For ease of comparison with Bayesian estimation results, in our discussion we consider Lubik and Schorfheide (2004) (from now on LS) estimates obtained for the Post-1982 period (and displayed in their Table 3) as representative estimates of the Bayesian approach. We focus on LS estimates because they estimate a similar NKM model, although they only consider the NKM model under the standard Taylor rule.

Paying attention to the estimates of the NKM under the forward-looking Taylor rule (the rule that exhibits the best fit) displayed in Table 1, we observe that the estimate of the discount factor, $\beta$, is similar to the estimate obtained in LS (that is, close to one but statistically different from one). The estimates for the structural parameters $\tau$ and $\kappa$ are higher than those obtained by LS and their standard deviations are large, which means that neither of them is statistically different from one. Moreover, looking at the estimates of these parameters under alternative policy rules, we observe that they are highly sensitive to the money rule specification. These results then suggest that a robustness analysis using alternative values for the structural parameters is required when studying the implications of different monetary policies.

As in LS, the policy parameter measuring the inertia in the Taylor rule, $\rho$, is close to one but statistically different from one. Moreover, the estimate of the parameter that captures the reaction of interest rate to the output gap, $\psi_{2}$, is significant and lies in the confidence interval estimated by LS. In contrast to LS, the policy parameter that monitors the response of interest rates to inflation, $\psi_{1}$, is less than one and is statistically different from zero and from one. By looking at the estimates of this parameter under alternative money rules, we observe that the estimate is also quite sensitive to the money rule specification. Interestingly, a point estimate for $\psi_{1}$ larger than one (although not statistically different from one) is obtained when a standard Taylor rule is assumed as in LS.

Looking at the parameters characterizing the shocks of the model, we observe that the estimated persistence of the IS-shock measured by $\rho_{g}$ is large and we cannot reject the presence of a unit root process (that is, $\rho_{g}$ is not statistically different from one and then $g$ follows a random walk). 
An explanation for this result is that the NKM model, a restricted VAR(1), needs a shock to be forced to follow a random walk process in order to match the highly persistent dynamics characterized by the auxiliary model, an unrestricted $\operatorname{VAR}(4)$, as described below. However, as in LS this result does not hold when assuming a standard Taylor rule. The Phillips curve shock also shows great deal of persistence as in LS (that is, $\rho_{z}$ is large), but we can reject the unit root hypothesis at the $10 \%$ significance level in this case. The size of the Phillips curve shock (measured by $\sigma_{z}$ ) is large and similar to that obtained by LS. Moreover, $\sigma_{z}$ is much larger than $\sigma_{g}$ and $\sigma_{\epsilon}$ as obtained in LS.

The random walk process identified in the IS-shock suggests that there is an omitted variable problem. For this reason, we further estimate a generalized version of the NKM model that includes habit formation à la Fuhrer (2000). The estimation results for this generalized version (not shown in this paper, but available from the authors upon request) show that the persistence of the IS-shock is substantially reduced by considering habit formation in consumption, but the estimate of the parameter measuring habit formation is poorly identified, showing a large standard deviation. Moreover, the model's fit, measured by the goodness-of-fit statistic, does not improve significantly when habit formation is included.

Finally, the estimate of the steady-state inflation rate, $\pi^{*}$, is much smaller than that of LS. The low value of $\pi^{*}$ may be capturing the decreasing trend of the inflation rate during most of the sample period considered. Interestingly, assuming a standard Taylor rule the point estimate is much closer to the point estimate obtained by LS than the one obtained with a forward-looking Taylor rule. This result suggests that by including expectational terms in the Taylor rule we may be capturing the decreasing inflation trend better.

\subsection{Estimation results in the Eurozone}

Table 2 and the second column in Table 3 show the estimation results for the Eurozone. As in the U.S., the value of the goodness-of-fit statistic clearly shows that the NKM model is not supported by the Eurozone data under any specification of the policy rule considered. The NKM model assuming a backward-looking Taylor rule provides the best fit. However, this fit is quite similar to the one obtained assuming either a forward-looking Taylor rule or an optimal monetary plan. More precisely, the fit improves by roughly 4.5\% moving from either of these two money rules to the backward-looking Taylor rule. The fit is reduced further (around 12\%) when moving from the standard Taylor rule to the backward-looking Taylor rule. 
Focusing on the estimates under the backward-looking Taylor rule displayed in Table 2, we observe that the estimate for $\beta$ is larger than that for the U.S. and is not statistically different from one. Moreover, in contrast to the U.S. case, the estimate of $\tau$ is small but statistically significant. As in the U.S., the estimate of $\kappa$ is large and not statistically different from one. In contrast to the U.S. case, the estimates of $\tau$ and $\kappa$ are quite robust to alternative specifications of the Taylor rule.

Looking at the policy parameters, we observe that the inertial parameter, $\rho$, is larger than in the U.S. and statistically different from one. In contrast with the U.S. empirical results, $\psi_{1}$ is statistically larger than one and $\psi_{2}$ is not statistically significant.

Looking at the parameters characterizing the shocks of the model, we observe that $\rho_{g}$ is not statistically different from one. Therefore, as occurs in the U.S., we cannot reject the hypothesis that the IS-shock follows a random walk (unit root) process. Moreover, the Phillips curve shock also shows great deal of persistence, but we can reject the unit root hypothesis as in the U.S. The estimates of the standard deviations of shocks are much smaller in the Eurozone than in the U.S. As in the U.S. case, the Phillips curve shock is larger than the IS-shock.

Finally, the estimate of the steady-state inflation rate is rather low but statistically significant and higher than that of the U.S. 
Table 1. Estimation results of NKM model for U.S.

\begin{tabular}{||llll||}
\hline \hline $\begin{array}{l}m=10 \\
p=45\end{array}$ & $\begin{array}{l}\text { Standard } \\
\text { Taylor Rule }\end{array}$ & $\begin{array}{l}\text { Forw-Look } \\
\text { Taylor Rule }\end{array}$ & $\begin{array}{l}\text { Backw-Look } \\
\text { Taylor Rule }\end{array}$ \\
\hline$J_{T}$ & 2.15847 & 1.29572 & 1.85772 \\
& 0.34172 & 0.99869 & 0.00458 \\
$(0.1394)$ & $(0.6317)$ & $(0.0202)$ \\
\hline$\beta$ & 0.99334 & 0.99314 & 1.00000 \\
& $(0.9309)$ & $(0.0018)$ & $(0.0338)$ \\
\hline$\rho$ & 0.87310 & 0.80673 & 0.98511 \\
& $(0.0284)$ & $(0.0713)$ & $(0.0134)$ \\
\hline$\kappa$ & 0.99834 & 0.91662 & 0.14428 \\
& $(1.1818)$ & $(0.3295)$ & $(0.0478)$ \\
\hline$\psi_{1}$ & 1.08420 & 0.21300 & 11.9360 \\
& $(0.2283)$ & $(0.1041)$ & $(15.995)$ \\
\hline$\psi_{2}$ & 0.36170 & 0.38530 & 1.14800 \\
& $(0.0696)$ & $(0.1128)$ & $(3.0223)$ \\
\hline$\rho_{g}$ & 0.94959 & 0.98541 & 0.89094 \\
& $(0.0176)$ & $(0.0197)$ & $(0.1082)$ \\
\hline$\rho_{z}$ & 0.91817 & 0.90870 & 1.00000 \\
& $(0.0274)$ & $(0.0533)$ & $(0.0058)$ \\
\hline$\sigma_{g}$ & 0.00850 & 0.17394 & 0.02822 \\
& $(0.0037)$ & $(0.1255)$ & $(0.0164)$ \\
\hline$\sigma_{z}$ & 0.06447 & 0.63255 & 0.00193 \\
& $(0.0897)$ & $(0.1348)$ & $(0.0264)$ \\
\hline$\sigma_{\epsilon}$ & 0.06543 & 0.05947 & 0.04066 \\
& $(0.0087)$ & $(0.0138)$ & $(0.0115)$ \\
\hline$\pi^{*}$ & 1.87880 & 0.24310 & 2.01900 \\
& $(0.2028)$ & $(0.1624)$ & $(0.3223)$ \\
\hline \hline \multirow{2}{*}{$(2)$} & & \\
\hline
\end{tabular}

Note: Standard errors in parentheses. 
Table 2. Estimation results of NKM model for the Eurozone

\begin{tabular}{|c|c|c|c|}
\hline $\begin{array}{l}m=10 \\
p=45\end{array}$ & $\begin{array}{l}\text { Standard } \\
\text { Taylor Rule }\end{array}$ & $\begin{array}{l}\text { Forw-Look } \\
\text { Taylor Rule }\end{array}$ & $\begin{array}{l}\text { Backw-Look } \\
\text { Taylor Rule }\end{array}$ \\
\hline$J_{T}$ & 2.55083 & 2.34517 & 2.23672 \\
\hline$\tau$ & $\begin{array}{l}0.29274 \\
(0.1339)\end{array}$ & $\begin{array}{l}0.31769 \\
(0.2011)\end{array}$ & $\begin{array}{l}0.12427 \\
(0.0638)\end{array}$ \\
\hline $\bar{\beta}$ & $\begin{array}{l}0.99978 \\
(0.3055)\end{array}$ & $\begin{array}{l}0.99916 \\
(1.9649)\end{array}$ & $\begin{array}{l}0.99996 \\
(0.1001)\end{array}$ \\
\hline$\rho$ & $\begin{array}{l}0.95514 \\
(0.0180)\end{array}$ & $\begin{array}{l}0.87520 \\
(0.0104)\end{array}$ & $\begin{array}{l}0.94219 \\
(0.0126)\end{array}$ \\
\hline$\kappa$ & $\begin{array}{l}0.99812 \\
(0.5766)\end{array}$ & $\begin{array}{l}0.99705 \\
(2.4740)\end{array}$ & $\begin{array}{l}0.99914 \\
(0.5012)\end{array}$ \\
\hline$\psi_{1}$ & $\begin{array}{l}2.33140 \\
(0.6948)\end{array}$ & $\begin{array}{l}2.20110 \\
(0.7917)\end{array}$ & $\begin{array}{l}1.80650 \\
(0.2438)\end{array}$ \\
\hline$\psi_{2}$ & $\begin{array}{l}0.37890 \\
(0.5435)\end{array}$ & $\begin{array}{l}0.05960 \\
(0.1110)\end{array}$ & $\begin{array}{l}0.58790 \\
(0.3901)\end{array}$ \\
\hline$\rho_{g}$ & $\begin{array}{l}0.99963 \\
(0.0016)\end{array}$ & $\begin{array}{l}0.97628 \\
(0.0119)\end{array}$ & $\begin{array}{l}0.99999 \\
(0.0003)\end{array}$ \\
\hline$\rho_{z}$ & $\begin{array}{l}0.88040 \\
(0.0450)\end{array}$ & $\begin{array}{l}0.99943 \\
(0.0035)\end{array}$ & $\begin{array}{l}0.91242 \\
(0.0357)\end{array}$ \\
\hline$\sigma_{g}$ & $\begin{array}{l}0.00706 \\
(0.0038)\end{array}$ & $\begin{array}{l}0.01876 \\
(0.0105)\end{array}$ & $\begin{array}{l}0.00328 \\
(0.0019)\end{array}$ \\
\hline$\sigma_{z}$ & $\begin{array}{l}0.04527 \\
(0.0307)\end{array}$ & $\begin{array}{l}0.20318 \\
(0.5201)\end{array}$ & $\begin{array}{l}0.01554 \\
(0.0107)\end{array}$ \\
\hline$\sigma_{\epsilon}$ & $\begin{array}{l}0.04396 \\
(0.0172)\end{array}$ & $\begin{array}{l}0.00000 \\
(0.0037)\end{array}$ & $\begin{array}{l}0.01325 \\
(0.0037)\end{array}$ \\
\hline$\pi^{*}$ & $\begin{array}{l}1.31990 \\
(0.4038)\end{array}$ & $\begin{array}{l}1.29970 \\
(0.4165)\end{array}$ & $\begin{array}{l}0.77640 \\
(0.2669)\end{array}$ \\
\hline
\end{tabular}

Note: Standard errors in parentheses. 
Table 3. Estimation results of the NKM model under "optimal" monetary policy rule

\begin{tabular}{||lll||}
\hline \hline $\begin{array}{l}p=45 \\
m=10\end{array}$ & U.S. & Eurozone \\
\hline$J_{T}$ & 2.19170 & 2.34265 \\
\hline$\tau$ & 0.32741 & 0.99996 \\
& $(0.2160)$ & $(0.5520)$ \\
\hline$\beta$ & 1.00000 & 0.99908 \\
& $(0.0053)$ & $(0.0025)$ \\
\hline$\kappa$ & 1.00000 & 0.61109 \\
& $(0.5725)$ & $(0.3911)$ \\
\hline$\lambda_{y}$ & 0.00000 & 0.99978 \\
& $(0.0365)$ & $(0.8055)$ \\
\hline$\lambda_{i}$ & 0.20300 & 0.15605 \\
& $(0.1363)$ & $(0.1092)$ \\
\hline$\rho_{g}$ & 0.99069 & 0.98701 \\
& $(0.0076)$ & $(0.0094)$ \\
\hline$\rho_{z}$ & 0.96515 & 0.72794 \\
& $(0.0274)$ & $(0.0967)$ \\
\hline$\sigma_{g}$ & 0.04514 & 0.08803 \\
& $(0.0288)$ & $(0.0562)$ \\
\hline$\sigma_{z}$ & 0.40175 & 0.15353 \\
& $(0.2263)$ & $(0.0513)$ \\
\hline$\pi^{*}$ & 2.30140 & 1.83340 \\
& $(0.5217)$ & $(0.2236)$ \\
\hline \hline Stant|| & $(29015$ & \\
\hline
\end{tabular}

Note: Standard errors in parentheses.

\subsection{Diagnostic tests}

Since the VAR residuals are orthogonal to the VAR dependent variables, the goodness-of-fit statistic can be decomposed into two terms: $J_{T}(\theta)=$ $J_{T}^{1}(\theta)+J_{T}^{2}(\theta)$, where $J_{T}^{1}(\theta)$ measures the distance associated with the systematic part of the VAR and $J_{T}^{2}(\theta)$ measures the distance associated with the residual features of the VAR. The estimation results obtained with the NKM model under a forward-looking Taylor rule using U.S data results in $J_{T}^{1}(\theta)=$ 1.2286 and $J_{T}^{2}(\theta)=0.0671$. Therefore, the NKM model has more trouble in accounting for the systematic part than for the non-systematic part of the 
VAR in the U.S. ${ }^{20}$ For the Eurozone, $J_{T}^{1}(\theta)=1.8014$ and $J_{T}^{2}(\theta)=0.4354$ is obtained under the backward-looking Taylor rule, which indicates that the NKM model has relatively more trouble in accounting for the non-systematic part than for the systematic part of the VAR.

The components of the vector $\left[H_{T}\left(\theta_{0}\right)-H_{N}(\theta)\right]$ contain information on how well the NKM model accounts for the estimates of the VAR (auxiliary) model. Larger components point to the estimates of the auxiliary model that the NKM has trouble accounting for. As suggested by Gallant, Hsieh and Tauchen (1997) the following quasi-t-ratios statistics can identify sources for model failure:

$$
\sqrt{1+\frac{1}{n}} \sqrt{T}\left[\left(\operatorname{diag}\left(W_{T}^{-1}\right)\right)_{i}^{1 / 2}\right]^{-1}\left[H_{T}\left(\theta_{0}\right)-H_{N}(\theta)\right]_{i} \quad \text { for } \quad i=1, \ldots, p,
$$

where $W_{T}$ is a consistent estimate of $W,\left(\operatorname{diag}\left(W_{T}^{-1}\right)\right)_{i}$ denotes the i-th element of the diagonal of matrix $W_{T}^{-1}$ and $\left[H_{T}\left(\theta_{0}\right)-H_{N}(\theta)\right]_{i}$ is the i-th element of $\left[H_{T}\left(\theta_{0}\right)-H_{N}(\theta)\right]$. In particular, a large $i$-th diagnostic statistic points to the fact that the NKM model does a poor job of fitting the $i$-th coefficient of the VAR model.

The second and third columns in Tables 4-5 show the VAR estimates and the corresponding standard errors using U.S. and Eurozone data sets, respectively. The last columns in Tables 4-5 show the corresponding quasi$t$-ratio diagnostic statistic (12) based on the version of the Taylor rule that provides the best fit in terms of the goodness-of-fit statistic. Looking at Table 4, we observe that the NKM model has trouble in accounting for output gap, inflation and interest rate persistence in the U.S. since for each equation some dependent variable lags are significant and the associated diagnostic statistic is large. Similarly, Table 5 shows that the NKM model has trouble in accounting for inflation and interest rate persistence in the Eurozone.

\footnotetext{
${ }^{20}$ Notice that $J_{T}^{1}(\theta)$ is computed based on 39 coefficients whereas $J_{T}^{2}(\theta)$ is based on 6 . Our conclusion is then based on the fact that the ratio $J_{T}^{1}(\theta) / J_{T}^{2}(\theta)=18.31$ is almost three times larger than the ratio $39 / 6$.
} 
Table 4. VAR estimates and diagnostic tests. U.S data

\begin{tabular}{|c|c|c|c|}
\hline \multirow[t]{2}{*}{ Variable } & Estimate & $\begin{array}{l}\text { Standard } \\
\text { error }\end{array}$ & $\begin{array}{l}\text { Diagnostic } \\
\text { statistic }\end{array}$ \\
\hline & Output & gap & equation \\
\hline constant & 0.02822 & 0.21597 & 0.17167 \\
\hline outputgap(1) & $1.08298^{* * *}$ & 0.13812 & -1.03583 \\
\hline outputgap $(2)$ & 0.12278 & 0.20806 & 2.06817 \\
\hline outputgap(3) & $-0.43018^{* *}$ & 0.20532 & -2.14141 \\
\hline outputgap (4) & 0.06394 & 0.14888 & 0.23319 \\
\hline inflation $(1)$ & -0.00607 & 0.08223 & -0.14368 \\
\hline inflation(2) & -0.09515 & 0.08626 & -1.44200 \\
\hline inflation(3) & -0.08597 & 0.09239 & -0.85738 \\
\hline inflation(4) & -0.02695 & 0.09422 & -0.35944 \\
\hline interest(1) & 0.20005 & 0.19672 & 0.63862 \\
\hline interest (2) & -0.27044 & 0.33066 & -0.55849 \\
\hline interest(3) & 0.25979 & 0.31978 & 0.96650 \\
\hline \multirow[t]{2}{*}{ interest(4) } & -0.11359 & 0.16827 & -0.94982 \\
\hline & Inflation & equation & \\
\hline constant & 0.44256 & 0.32386 & 2.63917 \\
\hline outputgap(1) & $0.34772^{*}$ & 0.20712 & 1.37843 \\
\hline outputgap $(2)$ & -0.14552 & 0.31200 & 0.13163 \\
\hline outputgap(3) & 0.17554 & 0.30789 & 0.44681 \\
\hline outputgap (4) & -0.20745 & 0.22326 & -0.69702 \\
\hline inflation(1) & $0.28204^{* *}$ & 0.12331 & -3.02670 \\
\hline inflation(2) & 0.07340 & 0.12935 & 0.30619 \\
\hline inflation(3) & $0.24108^{*}$ & 0.13854 & 0.94262 \\
\hline inflation(4) & $0.50003^{* * *}$ & 0.14129 & 3.90901 \\
\hline interest(1) & -0.27236 & 0.29500 & -2.59664 \\
\hline interest (2) & 0.12274 & 0.49586 & 0.43598 \\
\hline interest(3) & 0.38606 & 0.47953 & 1.40528 \\
\hline interest(4) & -0.35242 & 0.25233 & -1.57486 \\
\hline
\end{tabular}


Table 4. (Continued)

\begin{tabular}{||llll||}
\hline \hline Variable & Estimate & $\begin{array}{l}\text { Standard } \\
\text { error }\end{array}$ & $\begin{array}{l}\text { Diagnostic } \\
\text { statistic }\end{array}$ \\
& Interest & rate & equation \\
constant & 0.12225 & 0.13924 & -0.46812 \\
outputgap(1) & $0.31897^{* * *}$ & 0.08905 & 1.32905 \\
outputgap(2) & -0.08477 & 0.13414 & 0.19928 \\
outputgap(3) & -0.10315 & 0.13238 & -0.69668 \\
outputgap(4) & -0.03305 & 0.09599 & -0.18412 \\
inflation(1) & 0.04188 & 0.05302 & 1.37250 \\
inflation(2) & $0.12533^{* *}$ & 0.05561 & 1.58431 \\
inflation(3) & 0.04564 & 0.05957 & 0.88942 \\
inflation(4) & -0.00885 & 0.06075 & -0.36930 \\
interest(1) & $1.40855^{* * *}$ & 0.12684 & 2.59077 \\
interest(2) & $-0.67016^{* *}$ & 0.21319 & -3.45561 \\
interest(3) & 0.31650 & 0.20618 & 2.22761 \\
interest(4) & -0.16920 & 0.10849 & -1.06919 \\
& & & \\
s11 & VAR residuals & variance & matrix \\
s21 & 0.18560 & 0.25340 & 1.18205 \\
s31 & -0.07479 & 0.26022 & -0.21099 \\
s22 & 0.00980 & 0.11946 & -1.63557 \\
s23 & 0.41737 & 0.57359 & 0.54705 \\
s33 & 0.00231 & 0.18032 & 0.59025 \\
\hline \hline
\end{tabular}

Note: ***,**,* denote that the corresponding coefficient is statistically significant at the $1 \%, 5 \%$ and $10 \%$ levels, respectively. 
Table 5. VAR estimates and diagnostic tests. Eurozone data

\begin{tabular}{||llll||}
\hline \hline Variable & Estimate & $\begin{array}{l}\text { Standard } \\
\text { error }\end{array}$ & $\begin{array}{l}\text { Diagnostic } \\
\text { statistic }\end{array}$ \\
& & & \\
& Output & gap & equation \\
constant & $0.55970^{* *}$ & 0.22093 & 3.01980 \\
outputgap(1) & $0.94915^{* * *}$ & 0.21459 & 0.72121 \\
outputgap(2) & -0.00584 & 0.27354 & -0.15816 \\
outputgap(3) & -0.41740 & 0.28017 & -1.71858 \\
outputgap(4) & 0.31488 & 0.20974 & 1.99002 \\
inflation(1) & -0.04318 & 0.09813 & 0.23204 \\
inflation(2) & -0.03606 & 0.08801 & -0.30057 \\
inflation(3) & $-0.16344^{*}$ & 0.08870 & -2.69943 \\
inflation(4) & -0.04970 & 0.09608 & -0.40461 \\
interest(1) & 0.02741 & 0.22171 & -0.11723 \\
interest(2) & 0.10111 & 0.31599 & 0.42930 \\
interest(3) & 0.01670 & 0.31420 & -0.58612 \\
interest(4) & -0.13808 & 0.20025 & 0.29865 \\
& & & \\
constant & 0.69354 & 0.46858 & 1.19984 \\
outputgap(1) & 0.57352 & 0.45514 & 0.40695 \\
outputgap(2) & -0.67613 & 0.58016 & -1.19103 \\
outputgap(3) & 0.12720 & 0.59422 & 0.34153 \\
outputgap(4) & 0.49732 & 0.44484 & 1.05568 \\
inflation(1) & -0.01081 & 0.20812 & -3.56385 \\
inflation(2) & 0.04488 & 0.18667 & 0.17114 \\
inflation(3) & $0.43319 * *$ & 0.18812 & 2.36198 \\
inflation(4) & 0.17112 & 0.20377 & 1.10941 \\
interest(1) & 0.05784 & 0.47023 & -0.25923 \\
interest(2) & 0.71580 & 0.67019 & 1.48859 \\
interest(3) & -0.47347 & 0.66640 & -1.87885 \\
interest(4) & -0.28758 & 0.42472 & 0.58386 \\
\hline \hline
\end{tabular}


Table 5. (Continued)

\begin{tabular}{|c|c|c|c|}
\hline Variable & Estimate & $\begin{array}{l}\text { Standard } \\
\text { error }\end{array}$ & $\begin{array}{l}\text { Diagnostic } \\
\text { statistic }\end{array}$ \\
\hline & Interest & rate & equation \\
\hline constant & 0.20628 & 0.21218 & 2.55026 \\
\hline outputgap(1) & $0.35453^{*}$ & 0.20609 & -0.18566 \\
\hline outputgap (2) & -0.19802 & 0.26271 & 0.46764 \\
\hline outputgap (3) & -0.00729 & 0.26907 & -0.30755 \\
\hline outputgap(4) & -0.10663 & 0.20143 & 0.26037 \\
\hline inflation(1) & 1.33993 & 0.09424 & -0.22536 \\
\hline inflation(2) & -0.00845 & 0.08453 & -0.21021 \\
\hline inflation(3) & 0.19109 & 0.08518 & -2.83734 \\
\hline inflation(4) & -0.01318 & 0.09227 & -0.29179 \\
\hline interest (1) & $1.06230^{* * *}$ & 0.21293 & 0.21782 \\
\hline interest (2) & -0.04207 & 0.30347 & 0.06829 \\
\hline interest (3) & -0.29029 & 0.30175 & -1.10468 \\
\hline interest(4) & 0.22715 & 0.19232 & 1.46998 \\
\hline & VAR residuals & variance & matrix \\
\hline s11 & 0.05143 & 0.07273 & 4.30576 \\
\hline $\mathrm{s} 21$ & 0.01572 & 0.11020 & 0.02496 \\
\hline s31 & 0.02367 & 0.05477 & 2.91087 \\
\hline s22 & 0.23135 & 0.32717 & 0.20730 \\
\hline $\mathrm{s} 23$ & -0.00523 & 0.10489 & 0.62778 \\
\hline s33 & 0.04744 & 0.06708 & 0.89745 \\
\hline
\end{tabular}

Note: ***,**,* denote that the corresponding coefficient is statistically significant at the $1 \%, 5 \%$ and $10 \%$ levels, respectively.

\section{CONCLUSIONS}

We estimate a standard New Keynesian monetary (NKM) model under alternative specifications of the monetary policy rule using a classical econometric method based on the indirect inference principle. The estimation results show that several structural parameter estimates are quite sensitive to the specification of the monetary policy rule in the U.S. Furthermore, the estimation results in the U.S. show that the fit of the NKM under an optimal monetary plan is much worse than the fit of the NKM model assuming a forward-looking Taylor rule. In contrast to the U.S. case, the best fit in the 
Eurozone is obtained assuming a backward-looking Taylor rule, but the improvement is rather small with respect to assuming either a forward-looking Taylor rule or an optimal plan. Moreover, our estimation results show that the standard deviations of some structural parameter estimates are larger than those obtained using maximum-likelihood Bayesian methods. These estimation results may help to reconsider some of the prior distributions used in Bayesian estimation of NKM models.

Finally, our estimation results also point to a common finding obtained in the literature using alternative econometric approaches. Namely, the basic NKM model has trouble in accounting for the persistence observed in actual data.

\section{APPENDIX 1}

This appendix describes how to obtain the solution for the NKM model under the optimal monetary plan. The solution is found by solving the following matrix system:

$$
\Gamma_{0}^{o} \xi_{t}^{o}=\Gamma_{1}^{o} \xi_{t-1}^{o}+\Psi^{o} \epsilon_{t}^{o}+\Pi^{o} \eta_{t}^{o}
$$

where the superscript "o" stands for the NKM model under the optimal monetary plan and

$$
\begin{gathered}
\xi_{t}^{o}=\left(y_{t}, \pi_{t}, i_{t}, E_{t} y_{t+1}, E_{t} \pi_{t+1}, E_{t} \mu_{1 t+1}, E_{t} \mu_{2 t+1}, \mu_{1 t}, \mu_{2 t}, g_{t}, z_{t}\right)^{\prime}, \\
\eta_{t}^{o}=\left(\epsilon_{g t}, \epsilon_{z t}\right)^{\prime}, \\
\Gamma_{0}^{o}=\left(\begin{array}{ccccccccccc}
-1 & 0 & -\tau & 1 & \tau & 0 & 0 & 0 & 0 & 1 & 0 \\
\kappa & -1 & 0 & 0 & \beta & 0 & 0 & 0 & 0 & 0 & 1 \\
0 & -1 & 0 & 0 & 0 & 0 & 0 & 0 & -1 & 0 & 0 \\
-\lambda_{y} & 0 & 0 & 0 & 0 & 0 & 0 & -1 & \kappa & 0 & 0 \\
0 & 0 & 1 & 0 & 0 & 0 & 0 & \frac{\tau}{\lambda_{i}} & 0 & 0 & 0 \\
0 & 0 & 0 & 0 & 0 & 0 & 0 & 0 & 0 & 1 & 0 \\
0 & 0 & 0 & 0 & 0 & 0 & 0 & 0 & 0 & 0 & 1 \\
1 & 0 & 0 & 0 & 0 & 0 & 0 & 0 & 0 & 0 & 0 \\
0 & 1 & 0 & 0 & 0 & 0 & 0 & 0 & 0 & 0 & 0 \\
0 & 0 & 0 & 0 & 0 & 0 & 0 & 0 & 1 & 0 & 0 \\
0 & 0 & 0 & 0 & 0 & 0 & 0 & 1 & 0 & 0 & 0
\end{array}\right)
\end{gathered}
$$




$$
\Gamma_{1}^{o}=\left(\begin{array}{ccccccccccc}
0 & 0 & 0 & 0 & 0 & 0 & 0 & 0 & 0 & 0 & 0 \\
0 & 0 & 0 & 0 & 0 & 0 & 0 & 0 & 0 & 0 & 0 \\
0 & 0 & 0 & 0 & 0 & 0 & 0 & -\tau \beta^{-1} & -1 & 0 & 0 \\
0 & 0 & 0 & 0 & 0 & 0 & 0 & -\beta^{-1} & 0 & 0 & 0 \\
0 & 0 & 0 & 0 & 0 & 0 & 0 & 0 & 0 & 0 & 0 \\
0 & 0 & 0 & 0 & 0 & 0 & 0 & 0 & 0 & \rho_{g} & 0 \\
0 & 0 & 0 & 0 & 0 & 0 & 0 & 0 & 0 & 0 & \rho_{z} \\
0 & 0 & 0 & 1 & 0 & 0 & 0 & 0 & 0 & 0 & 0 \\
0 & 0 & 0 & 0 & 1 & 0 & 0 & 0 & 0 & 0 & 0 \\
0 & 0 & 0 & 0 & 0 & 0 & 1 & 0 & 0 & 0 & 0 \\
0 & 0 & 0 & 0 & 0 & 1 & 0 & 0 & 0 & 0 & 0
\end{array}\right),
$$

Notice that the system (A.1) is composed of equations (1), (2), (9), (10), (11), (4), (5) and the following appended identities:

$$
\begin{aligned}
& y_{t}=E_{t-1} y_{t}+\left(y_{t}-E_{t-1} y_{t}\right), \\
& \pi_{t}=E_{t-1} \pi_{t}+\left(\pi_{t}-E_{t-1} \pi_{t}\right),
\end{aligned}
$$




$$
\begin{aligned}
& \mu_{2 t}=E_{t-1} \mu_{2 t}+\left(\mu_{2 t}-E_{t-1} \mu_{2 t}\right), \\
& \mu_{1 t}=E_{t-1} \mu_{1 t}+\left(\mu_{1 t}-E_{t-1} \mu_{1 t}\right) .
\end{aligned}
$$

These identities show up when implementing the simple rule suggested by Sims (2002): when terms of the form $E_{t} x_{t+s}$ appear, we simply make a sequence of those variables and equation creations that involve one period forecast errors.

\section{APPENDIX 2}

This appendix describes the time series considered.

Economic activity indexes:

- GDP: quarterly, seasonally adjusted data. Period: 1987:3-2004:3. Source: U.S. Department of Commerce, Bureau of Economic Analysis.

- Real potential GDP: quarterly data. Period: 1987:3-2004:3. Source: U.S. Congress, Congressional Budget Office.

- GDP: quarterly, seasonally adjusted data. Period: 1994:1-2004:3. Source: OECD statistics.

Price level indexes:

- U.S. implicit price deflator of GDP: quarterly, seasonally adjusted data. Period: 1987:3-2004:3. Source: U.S. Department of Commerce, Bureau of Economic Analysis

- Eurozone implicit price deflator of GDP: quarterly, seasonally adjusted data. Period: 1994:1-2004:3. Source: OECD statistics.

Interest rates:

- Federal funds rate: quarterly data. Period: 1987:3-2004:3. Source: Board of Governors of the Federal Reserve System.

- 3-month Euribor interbank rate: quarterly data. Period: 1994:1-2004:3. Source: OECD statistics. 


\section{References}

[1] Amato, Jeffrey D., and Thomas Laubach (2003) "Estimation and control of an optimization-based model with sticky prices and wages," Journal of Economic Dynamics and Control 27, 1181-1215.

[2] Boivin, Jean, and Marc P. Giannoni (2003) "Has monetary policy become more effective?," Columbia University mimeo.

[3] Calvo, Guillermo (1983) "Staggered prices in a utility-maximizing framework," Journal of Monetary Economics 12, 383-398.

[4] Canova, Fabio (2004) "Monetary policy and the evolution of U.S. economy: 1948-2002," IGIER mimeo.

[5] Cassou, Steven P. (1989) "Stochastic Dynamic Tax Analysis," unpublished Ph.D. dissertation, University of Minnesota, Minneapolis.

[6] Cochrane, John H. (2001) Asset Pricing, Princeton University Press, Princeton.

[7] Cogley, Timothy, and Thomas J. Sargent (2002) "Drifts in Volatilities: Monetary Policies and Outcomes in the Post WWII U.S.," Arizona State University, mimeo.

[8] Duffie, Darrell, and Kenneth J. Singleton (1993) "Simulated moments estimation of Markov models of asset prices," Econometrica 61, 929-952.

[9] Fuhrer, Jeffrey C. (2000) "Habit formation in consumption and its implications for monetary policy models," American Economic Review 90, 367-390.

[10] Galí, Jordi (2002) "New perspectives on monetary policy, inflation and the business cycle," National Bureau of Economic Research Working Paper 8767.

[11] Galí, Jordi, and Mark Gertler (1999) "Inflation dynamics: a structural econometric analysis," Journal of Monetary Economics 44, 195-222.

[12] Gallant, A. Ronald, and George Tauchen (1996) "Which moments to match?" Econometric Theory 12, 657-681.

[13] Gallant, A. Ronald, David Hsieh, and George Tauchen (1997) "Estimation of stochastic volatility models with diagnostics," Journal of Econometrics 81, 159-192. 
[14] Giannoni, Marc P., and Michael Woodford (2003) "How forward-looking is optimal monetary policy?," Journal of Money, Credit, and Banking $35,1425-1469$.

[15] Goodfriend, Marvin (1991). "Interest Rates and the Conduct of Monetary Policy", Carnegie-Rochester Conference Series on Public Policy 24, 231-274.

[16] Goodfriend, Marvin and Robert G. King (1997) "The New Neoclassical synthesis and the role of monetary policy," Macroeconomics Annual 231283.

[17] Gouriéroux, Christian, and Alain Monfort, (1996) Simulation-Based Econometric Methods. Oxford University Press, Oxford.

[18] Gouriéroux, Christian, Alain Monfort, and Eric Renault (1993) "Indirect inference," Journal of Applied Econometrics 8, s85-s118.

[19] Gutiérrez, María-José, and Jesús Vázquez (2004) "Switching equilibria. The present value model for stock prices revisited," Journal of Economic Dynamics and Control 28, 2297-2325.

[20] Ireland, Peter N. (2004) "A method for taking models to the data," Journal of Economic Dynamics and Control 28, 1205-1226.

[21] Kydland, Finn E., and Edward. C. Prescott (1977) "Rules rather than discretion: the inconsistency of optimal plans," Journal of Political Economy 85, 473-491.

[22] Lee, Bong-Soo, Ingram, Beth F. (1991) "Simulation estimation of timeseries models," Journal of Econometrics 47, 197-205.

[23] Lowe, P. and Ellis, L. (1997) "The smoothing of official interest rates" in Lowe, P.(ed.) Monetary Policy and Inflation Targeting Proceedings of a Conference, Reserve Bank of Australia.

[24] Lubik, Thomas A., and Frank Schorfheide (2003) "Computing sunspot equilibria in linear rational expectations models," Journal of Economic Dynamics and Control 28, 273-285.

[25] Lubik, Thomas A., and Frank Schorfheide (2004) "Testing for indeterminacy: an application to U.S. monetary policy," American Economic Review 94, 190-217. 
[26] María-Dolores, Ramón, and Jesús Vázquez (2004) "The New Keynesian monetary model: Does it show the comovement between output and inflation in the US?" Universidad del País Vasco, mimeo. Accepted for presentation at the ESWC2005 (London) and the 20th Congress of the EEA (Amsterdam).

[27] McCallum, Bennett T., and Edward Nelson (1999) "An optimizing ISLM specification for monetary policy and business cycle analysis," Journal of Money, Credit, and Banking 31, 296-316.

[28] Rabanal, Pau, and Juan F. Rubio-Ramírez (2005) "Comparing New Keynesian models of the business cycle: A Bayesian approach," Federal Reserve Bank of Atlanta working paper 2001-22 (Revised version).

[29] Rotemberg, Julio J., and Michael Woodford (1995) "Dynamic general equilibrium models with imperfectly competitive product markets," in Timothy F. Cooley (ed.) Frontiers of Business Cycle Research, Princeton: Princeton University, pp. 243-293.

[30] Rotemberg, Julio J., and Michael Woodford (1997) "An optimizingbased econometric model for the evaluation of monetary policy," NBER Macroeconomics Annual, Cambridge, MA: MIT Press, pp. 297-346.

[31] Sack, Brian (1997) "Uncertainty and gradual monetary policy," Federal Reserve Board, mimeo.

[32] Sims, Christopher A. (2002) "Solving linear rational expectations models," Computational Economics 20, 1-20.

[33] Sims, Christopher A., and Tao Zha (2004) "Were There Regime Switches in US Monetary Policy?," Princeton University, mimeo.

[34] Smets, Frank, and Raf Wouters (2003) "An estimated dynamic stochastic general equilibrium model of the Eurozone," Journal of the European Economic Association 1, 1123-1175.

[35] Smith, Anthony A. (1993) "Estimating nonlinear time-series models using simulated vector autoregressions", Journal of Applied Econometrics 8, s63-s84.

[36] Woodford, Michael (2003) "Optimal interest-rate smoothing," Review of Economic Studies 70, 861-886.

[37] Yun, Tack (1996) "Nominal price rigidity, money supply endogeneity, and business cycles," Journal of Monetary Economics 37, 345-370. 